\title{
NOTES ON THE CANADA PORCUPINE IN THE MARITIME PROVINCES ${ }^{1}$
}

\author{
By W. A. REEKS
}

Dominion Entomological Laboratory, Fredericton, N.B.

\begin{abstract}
The Canada porcupine is discussed mainly from the standpoint of damage and control. The paper is based on the analysis of a questionnaire issued to foresters and forest rangers and is supplemented by data from the literature and some original observations.

Feeding on forest trees is extensive in parts of New Brunswick and Nova Scotia but since all of the trees attacked are not crop trees serious damage to the stand does not always follow. Damage is severe in damage to the stand does not always follow. Damage is severe in
localized areas where the stands are of particular value, as in planta. tions, experimental areas and around camp sites.

The only method of large-scale control ever attempted in the Maritime Provinces has been the bounty system. While the effectiveness of this method has not been carefully studied, it appears from parallel cases in the United States that the bounty system is generally expensive for the degres of control effected. Control methods probably serve best if applied intensively to small areas where the damage is most serious. A method of localized control by den poisoning is discussed.
\end{abstract}

$\mathrm{T}$

HE CANADA porcupine is one of the best known rodents inhabiting the forests of Eastern Canada. Its unusual armature, slow gait and habit of removing bark from trees are known to all but opinions on the importance of the injury it does and the need for control are varied and contradictory. Owing to frequent enquiries regarding these points, a questionnaire was sent to a number of rangers and foresters as part of the work of the Forest Insect Survey at the Fredericton Laboratory. The following is an analysis of the 147 answers received, supplemented by data from the literature, particularly Taylor (5), correspondence with Mr. D. A. Spencer, District Investigator of the Wildlife Research Field Station, Poughkeepsie, N.Y., and some observations of the writer.

\section{Distribution}

The answers show that the porcupine occurs in all of the counties of New Brunswick and apparently throughout the mainland of Nova Scotia, though some of the counties of the latter province were not heard from.

The rodent evidently does not occur on Prince Edward Island. This is supported by correspondence from several individuals familiar with the wooded areas of that province, and it was not mentioned by Bain (1), either among extinct or present species discussed by him. It is doubtful if the porcupine has ever reached any of the islands off the Maritime Provinces. Dr. R. M. Anderson, Chief of the Division of Biology, National Museum, Ottawa, has no record of it from the islands of Cape Breton, Grand Manan and Campobello, and the reports from four rangers indicate that it is not present on these islands.

ABundance

The habits of the porcupine make an estimate of its abundance very difficult. While essentially a solitary species, the animal is nevertheless

1. Contribution No. 2195, Division of Entomology, Science Service, Dominion Department of Agriculture, Ottawa, Canada. 
attracted to certain sites, such as deserted camp yards, rocky ledges, etc., which are often used for denning. Furthermore, it is known that some species have strong migratory habits and Taylor (5) points out that their movements in the Southwestern States take place over fairly definite areas known as "travel-ways." These may or may not be well defined by the extent of feeding on trees. In some localities travel-ways may not exist but where they do any estimate of population for any given locality may be very rough indeed.

The co-operators gave an average estimate of the number encountered per year as 46 in New Brunswick and 44 in Nova Scotia. Also, the average of the estimates of population by 61 co-operators in New Brunswick was 7 per square mile. In this latter case there is a striking agreement, though perhaps accidental, with actual counts of a related species in Arizona (5), where the population on a 323,500 acre tract of land averaged about 8 per square mile.

If estimates of the population per square mile and the number encountered per year are taken as criteria of porcupine abundance, the rodent appears to be particularly numerous in the following counties of New Brunswick: Charlotte, Northumberland, Gloucester, York, Sunbury, and possibly Madawaska.

Some indication of the abundance of porcupines in York County, N.B., is shown by the number encountered by the writer in 1941. From May 16 to October 31, some 15 were seen along a total of 125 miles of woods trail. This suggests a population close to the 7 per square mile as given in the above estimate.

Factors Governing AbUNDANCE

The most important factors governing abundance are reproductive rate, length of life and natural enemies.

The reproductive rate, compared with most of the rodents, is low. There is but one generation a year and accounts in the literature indicate that the number of young does not usually exceed one per female. Most of the cooperators agreed that one or two young were the usual number; and one co-operator, Mr. J. D. Levasseur, stated that of 22 females he dissected one winter, all contained a single embryo.

The porcupine is apparently long-lived, but due to the diffculty of rearing the animal in captivity little is known about its life span. There is one record of an albino porcupine having been seen for six successive years (5). The normal length of life may well be longer. The protection of its quills is very effective, though the porcupine does have some natural enemies.

Among the predators that attack the porcupine are the fisher, bobcat, bear, wolf, fox, and to a lesser extent, the great horned owl and the eagle (5). In New Brunswick and Nova Scotia the fisher is probably the most capable of the predators because trappers frequently report finding remains of the rodent in fisher dens. The fisher, however, is scarce compared with the bobcat and fox. During the period 1924 to 1940 an average of only 42 royalities were received by the Province of New Brunswick for fisher. While this represents only a portion of the total population, it does suggest relative scarcity and some woodsmen are of the opinion that the population of the fisher is declining in New Brunswick. 
Porcupines are also attacked by a number of parasites. During the summer of 1941 eight specimens were dissected and examined for the presence of parasites. All were free from ticks, fleas, and lice. Tapeworms were numerous in the small intestine of 7 specimens, and roundworms were numer. ous in the large intestine of all 8 specimens. In spite of the fact that flatworms were so abundant as frequently to cause congestion of the intestines, the animals appeared to be healthy and it is doubtful if these parasites have any control value. Porcupines suffer from a variety of diseases (5) but little is known about the degree of mortality from pathogenic organisms.

Man perhaps destroys more porcupines than all of the natural enemies together. Some indication of the proportion so destroyed is shown by the results of the questionnaire. The average estimate of the proportion killed by 107 co-operators was 40 per cent of all porcupines encountered. While large numbers are so destroyed, man at the same time creates conditions by cutting or planting that are very favourable to the porcupine.

\section{Trees Attacked}

According to Spencer (4), hemlock holds first place on the porcupine's menu and sugar or hard maple is the second choice for food. Although hemlock is not abundant in New Brunswick, it was reported as the favourite food by co-operators in the counties of Carleton, York and Kent. Maple was given first place in Madawaska and Restigouche counties. Taking the Province of New Brunswick as a whole, spruce was given most frequently as the favourite tree, followed by pine, larch, fir, hemlock, birch, beech, maple, and poplar. In Nova Scotia, the order of preference was as follows: spruce, birch, hemlock, fir, beech, larch, maple, and pine. It is probable that there are local preferences, depending on the abundance of the various tree species. Since the porcupine feeds on almost any tree, it can thrive on other species if the preferred tree is not available.

\section{FEEding Habits}

There are seasonal variations in the feeding habits of the porcupine. In the spring and summer months herbaceous growth constitutes the main diet. It is during this period that seedlings, grass, foliage, and only small quantities of inner bark of trees are eaten. In the late autumn and winter months the inner bark of trees is the main source of food.

The feeding on the bark of young trees may be seen on any part of the stem and frequently the stem is almost completely stripped. This applies particularly to balsam, larch, and spruce. In other instances patches of bark of varying size are removed.

On mature trees feeding on the bark is generally confined to the upper part of the stem and branches, where the bark is removed in patches. One exception to this is a type of feeding common on beech. In mature beech stands the porcupine confines its feeding mainly to the base of the trees. Here patches of bark, not generally exceeding half of the circumference of the stem, are eaten. Seldom are the trees completely girdled and usually these trees show no other signs of feeding farther up the stem or among the branches. It is not clear why beech is so often attacked in this manner, but it appears that the bark is thin or palatable enough at the base to provide satisfactory 
food without necessitating climbing. Whatever the reason may be, this habit results in a small amount of feeding on a large number of trees and often over half of the mature beech in extensive areas are so attacked.

In feeding on the branches, not only may the bark be removed but the branches may also be completely severed from the stem.

Heavy feeding is generally more or less localized. It is particularly severe in the vicinity of camp sites and rocky ledges, which offer good denning facilities. Curtis (2) has shown that the number of trees attacked decreases with the distance from the dens.

DAMAGE

The degree of damage caused by porcupines is not easily appraised. Probably the most noticeable damage results from girdling of merchantable trees. The removal of smaller patches of bark allows for the entry of sap rot and the dying of the bark above the injury makes peeling for pulp more difficult.

Feeding by porcupines may cause serious damage to a lightly stocked stand. After the hurricane in New England in 1938 the increased shrub and herbaceous growth provided an abundance of summer food and damage to the few standing trees in large blowdown areas was soon in evidence. Feed. ing caused considerable mortality of the remaining hemlock and suppression of rock maple (4).

Feeding on seedlings and saplings causes extensive damage in plantations. Young trees and herbaceous growth that develop in thinning plots are attractive to the porcupine and in a short time the damage is extended to the crop trees.

Porcupines are very fond of salt and it is largely due to the presence of salt in certain wood materials that damage is done to camps.

On the other hand, all porcupine feeding does not necessarily constitute damage. Some trees attacked are defective from other causes and the girdling and killing of some suppressed trees may actually improve the stand.

Figures on actual mortality on a 7.2 acre plot in Sunbury County have been provided by Mr. R. F. Morris. This stand is approximately fifty years of age and is composed mainly of black spruce with smaller volumes of other species, including white spruce, larch, pine, birch and maple. All trees above 1 inch D.B.H. were tallied in 1939, when the total volume amounted to 8,266 cubic feet. The average annual mortality from porcupine feeding, based on three subsequent tallies, was approximately one-half of 1 per cent by volume. The highest mortality was among larch from 1 to 3 inches D.B.H. Considering that many of the trees destroyed were not crop trees, the loss has not been very heavy in spite of the fact that porcupines are numerous in this area. However, no attempt was made to analyze the injury to other trees that were still living.

It is generally recognized that damage is at a minimum in fully stocked mature stands. This is supported by strip cruises carried out by Mr. G. W. Barter in a virgin balsam-spruce stand in the Gaspé. Of 10,952 stems (4" to $15^{\prime \prime}$ ) tallied on the Upper Cascapedia River in 1941, only two had been killed by porcupines. Porcupines are common in this area, although the mortality caused by them appears to be negligible.

In addition to damage to forests, some consideration must be given to 
injury to farm crops. One ranger from Gloucester County, N.B., reported severe damage to clover fields and two others, one from Charlotte County and one from St. John County, indicated that damage to grain fields was heavy. It was also largely due to damage to grain fields that Cumberland County, N.S., one year paid a bounty on porcupines.

\section{CONTROL}

Taylor (5) is of the opinion that the ultimate solution of the porcupine problem lies in management. Some of the principles of management he recommends are: maintaining density of stand, promoting vigour of growth, and encouraging a certain number of fur-bearing and predatory animals. Such management has very limited application at present and direct control measures may be necessary sometimes. Several means of control have been tried but only two are discussed here,- the bounty system and den poisoning.

The bounty system has occasionally been resorted to in the New England States and Maritime Provinces, but, unforturiately, the effectiveness of the bounty has been little studied. The State of Maine once appropriated \$1,000 for a two-year period to pay a bounty on porcupines. The result was a deficit of $\$ 20,000(5)$. The same state paid out $\$ 171,000$ on porcupine bounties in nine years. Vermont once offered a bounty on porcupines, but in 1923 it was considered as ineffective and the law was repealed. New Hampshire still pays a bounty of 20 cents a snout.

In Nova Scotia, the late F. J. D. Barnjum paid 10 cents per porcupine some time prior to 1925 . The County of Cumberland paid 50 cents per animal from July to December, 1930. In this short period approximately 12,000 bounties were paid out by the county and, to quote one associated with the project, "It must have had some effect in extinguishing the animal, for the Council at its first opportunity revoked the bounty and since that time even the word "porcupine' has been somewhat of a rarity."

Bounties have also been offered in New Brunswick. Fish and game clubs in this province have paid bounties on licensed areas to trusted employees, with a view to protecting camps and camp sites. One member of such a club states that this has been very effective locally. The province offered a bounty of 50 cents per animal from the autumn of 1918 to the early spring of 1920 . During this period the total sum paid out amounted to $\$ 5,368.50$, most of which was spent in 1919. A bounty at the same rate was again offered by New Brunswick in 1942 and it remains to be seen what results will be achieved.

The bounty system has not generally been satisfactory. It is expensive in relation to the control effected. Many porcupines are killed in areas where no control is necessary and, conversely, control may be inadequate where it is most needed. There seems to have been no attempt to measure the degree of control effected. Bounties are frequently paid on animals killed outside of the control area and it has been reported in Nova Scotia that some individuals were adept at making the skin from paws resemble snouts, thereby collecting five bounties on one animal. However, the bounty system may have its place in local areas.

It is concluded by Taylor (5) that "our survey of the various control methods suggests that of all the proposed instrumentalities (of control) the 
bounty system is probably the worst. As in other cases, the bounty method puts a premium on fraud, is exceedingly costly and, due to its non-effectiveness when porcupines become scarce, is likely to leave a good many porcupines in the control area."

Since porcupine damage is generally localized, a system of localized control is often advocated. Spencer (4) is perfecting a system of localized control by den poisoning but the details of the method are as yet unpublished.

Den treatment is discussed in some detail by Taylor (5). By his method all possible dens are located and poisoned blocks of wood are placed far enough into the dens to be protected from storms and out of reach of livestock. A salt-thallium or salt-strychnine is used (1 ounce of powdered alkaloid strychnine to 16 ounces of salt), the poison being placed in 2 -inch auger holes in the block. A possible objection to den poisoning is that harmless rodents may also be killed.

Discussion

That porcupines cause considerable damage in localized areas cannot be denied. The animal, however, has a few good qualities which may be overlooked. An argument frequently presented as a reason for protecting the animal is the fact that it is a source of food for travellers lost in the forest since it is easily overtaken and clubbed. There are some who consider the flesh of the animal a delicacy, and in Yarmouth County, N.S., Acadians organize parties to hunt the animal for this purpose. In New Brunswick it has been used to some extent for fox food. In addition, porcupines destroy bark infected with pine blister rust (3) and thereby remove part of the source of infection of this disease. It is also reported that the delimbing of trees by porcupines provides deer with browse when the snow is deep. In park lands they are of considerable interest as a nature study.

Unfortunately, the damage caused by porcupines sometimes makes control measures necessary. Before they are adopted, all aspects of forest management relating to the problem should be considered. Evidence to date sug. gests that den poisoning is the cheapest and most effective method of control. The bounty system is not generally satisfactory but has promise of success if applied locally.

\section{References}

(1) Bain, Francis. 1890. Natural History of Prince Edward Island. 123 pp.

(2) Curtis, J. D. 1941. The silvicultural significance of the porcupine. Jour.

(3) Spaulding, P. 1022 Forestry, 39: 583-594.

(3) Spaulding, P. 1922. Investigations of the white pine blister rust. U. S. D. A. Bull. 957, pp. 1-100.

(4) Spencer, D. A. 1941. The porcupine as a factor in regeneration of hurricane areas. Fox Forest Notes, No. 29. New Hampshire Forestry and Recleation Department.

(5) Taylor, W. P. 1935. Ecology and life history of the porcupine (Erethizon epixanthum) as related to the forests of Arizona and the southwestern United States. Univ. of Arizona Bulletin, Biol. Sci. Bull. No. 3, 6 (5) : 1-177. 